\title{
Biomedical Waste Management (BMW) Assessment at the RHC Regional Hospital in Tangier, Morocco
}

\author{
Amina El Morhit ${ }^{1 *}$, Mohamed El Morhit ${ }^{2}$, Nadira Mourabit ${ }^{3}$, and Mimoun Zouhdi ${ }^{4}$ \\ 1,2,4 Laboratory of Microbiology, Research Team Health, Water and Environment. Faculty of Medicine and Pharmacy. \\ University Mohammed-V, Rabat, Morocco \\ ${ }^{3}$ Laboratory of the medical analysis the hospital Mohammed V. Tangier, Morocco
}

\begin{abstract}
Biomedical waste is a real danger to public health and the environment. The quantity of this waste, mainly from hospitals, is constantly increasing, leading to various forms of pollution. This is a cross-sectional, observational study that took place in 2017. A questionnaire was submitted to nurses, doctors and those responsible for hospital hygiene and the operation of waste incinerators to assess the mechanisms and knowledge of medical staff in terms of biomedical waste management. It was confirmed that the hospital wastes are still poorly managed due to the absence of a plan or program for MPSD in all the structures studied, which attests to the non-application of the regulations in force and an inadequate internal management system in most laboratories. Due to the non-availability of health technicians and the lack of material resources in quality and quantity, a staff that is poorly informed about the regulations that apply to BMW, and a poorly recognized and disrespected BMW process that breaks even the clearest instructions regarding incineration and landfill disposal. It has become very urgent to adopt new strategies to be planned for an adequate training to be included for better medical waste management.
\end{abstract}

\section{Introduction}

Biomedical waste is a public health problem worldwide. It presents health risks to hospital staff and to the population in contact with this waste [1]. The management of biomedical waste involves various stages: sorting, collection, storage, transport, destruction and disposal [2]. Incorrect management of BMW contributes to environmental pollution, unpleasant odors, the growth and multiplication of insects, rodents and worms, and can lead to the transmission of infectious diseases such as typhoid fever, cholera and hepatitis as a result of injuries caused by sharps contaminated with human blood [3]. Disposal of these wastes requires consideration of specific technical rules to enable better management and adequate treatment [4]. This requires the adoption of an appropriate hygiene policy, sufficient human, material and financial resources, trained personnel and adequate regulations to prevent or even reduce any risk to patients, professionals and the environment [5]. The management of BMW is described as the process of ensuring healthcare, the protection of the personal employees and the safety of the community. It includes the planning, acquisition, training and behaviour of health care staff, the correct use of tools, equipment and pharmaceuticals, treatment methods appropriate to the health care setting inside or outside the health care setting, and evaluation [2.6]. In 22 developing countries, the number of institutions that have adequately implemented DBM elimination varies from $18 \%$ to $64 \%$ according to WHO [7]. In Morocco, the competent authorities are committed to implementing actions aimed at prevention and hygiene protection in health care institutions, including a system for managing waste generated by health care institutions, whose primary objective is to prevent accidental transmission of diseases and improve the quality of care [8]. Article 87 of Morocco's hospital bylaws stipulates that the hospital director must ensure that the rules of hygiene and cleanliness of hospital premises are respected by users, staff, and visitors. To this end, he takes all necessary preventive and awareness measures. Thus, the management and disposal of medical and pharmaceutical waste must be carried out in accordance with the applicable legislation and regulations [10]. In hospitals, the management of this waste is part of the policy of continuous improvement of the quality and safety of care. It also contributes to the prevention of adverse events related to the activities of healthcare institutions, including the prevention of healthcare-associated infections and accidents related to blood exposure [11]. The present study was carried out in the Mohammed

\footnotetext{
* Corresponding author: amina.elmorhit@gmail.com
} 
V Hospital of Tangier, to evaluate the quality of management of biomedical hospital waste with a view to its improvement.

\section{Population and Methods}

\subsection{Population}

This study was carried out at the Mohammed V Hospital in Tangier in 2017, given its reputation and history that make this institution a pilot in the management of hospital infectious waste. The sampling in this study is probabilistic for nurses, doctors and the hygiene manager of a size of 180 caregivers. In order to provide answers to preconceived research questions, the study was oriented towards description and exploration. This is an exploratory descriptive study based on quality assessment of biomedical waste management.

\subsection{Methods}

In order to gather different points of view to investigate the converging aspects, the study used a variety of data sources:

Direct observation enabled us to appreciate the process and the immediate results of waste management. The observation was made using an observation grid. The semi-directive interviews were carried out with the head of hygiene, doctors, nurses and certain stakeholders in the management of biomedical waste, respecting confidentiality after informing the interested parties about the objective of our study. Compulsion of certain documents such as documents that are related to the actions of the different actors concerning the biomedical waste management process. A questionnaire for caregivers; nurses in the care units and doctors, which represents the category exposed to the most frequent contacts with BMW.

\section{Results}

\subsection{Quantitative Component}

\subsubsection{Observation results}

Of the 92 service providers observed $53.18 \%$, health care workers do not sort waste from the moment it is produced, whereas $46.82 \%$ of the responses observed that rules for sorting and packaging waste are respected by staff. Our field observations confirm that only $53.88 \% \quad(n=97)$ of caregivers wear protective equipment when sorting and packaging waste. The most commonly used protective equipment is gloves. The use of safety boxes was consistently used for the collection of prickly waste in $25.73 \%$. In the majority of observation situations, waste packaging equipment is available, but in insufficient quantities. In $47.9 \%$ of the observations we made $(n=81)$, confirm that there is a lack of a clear system on the management of hospital waste, and more than a $32.52 \%$ confirms that there is no procedure to follow in case of injury/cut-off by hospital waste.76.54\% or effective $(n=137)$ Respondents say they lack knowledge about how to treat or dispose of contaminated waste. In 50.56\% of the observations we made, we noted the lack of adequate equipment for the collection and internal transport of waste produced by the different departments of the hospital.

\subsubsection{Results of the questioning}

\subsubsection{Demographic and occupational characteristics}

Physicians accounted for $37.67 \%$ of this staff, nurses $58.89 \%$ and the other $9.44 \%$ Of which $48.33 \%$ are male and $51.67 \%$ are female (Table 1).

Table 1. Demographic and occupational characteristics.

\begin{tabular}{|c|c|c|c|c|c|}
\hline & & ni & $\Sigma$ & $\begin{array}{l}\mathbf{f i} \\
(\%)\end{array}$ & Fi (\%) \\
\hline \multirow[t]{3}{*}{$\begin{array}{c}\text { Professio } \\
\text { n }\end{array}$} & Nurses & $\begin{array}{l}1 \\
0 \\
6\end{array}$ & \multirow{23}{*}{$\begin{array}{l}1 \\
8 \\
0\end{array}$} & $\begin{array}{c}58,8 \\
9\end{array}$ & 58.89 \\
\hline & Doctors & $\begin{array}{l}5 \\
7 \\
\end{array}$ & & $\begin{array}{c}31,6 \\
7 \\
\end{array}$ & 90.56 \\
\hline & Others & $\begin{array}{l}1 \\
7\end{array}$ & & 9,44 & 100 \\
\hline \multirow[t]{3}{*}{ Age } & $20-30$ & $\begin{array}{l}8 \\
6 \\
\end{array}$ & & $\begin{array}{c}47,7 \\
8\end{array}$ & 47.78 \\
\hline & $30-50$ & $\begin{array}{l}4 \\
3 \\
\end{array}$ & & $\begin{array}{c}23,8 \\
9\end{array}$ & 71.67 \\
\hline & $<50$ & $\begin{array}{l}5 \\
1 \\
\end{array}$ & & $\begin{array}{c}28,3 \\
3\end{array}$ & 100 \\
\hline \multirow[t]{2}{*}{ Sex } & Male & $\begin{array}{l}8 \\
7 \\
\end{array}$ & & $\begin{array}{c}48,3 \\
3 \\
\end{array}$ & 48.33 \\
\hline & Female & $\begin{array}{l}9 \\
3 \\
\end{array}$ & & $\begin{array}{c}51,6 \\
7 \\
\end{array}$ & 100 \\
\hline \multirow[t]{8}{*}{ Services } & Surgery & $\begin{array}{l}5 \\
3 \\
\end{array}$ & & $\begin{array}{c}29,4 \\
4 \\
\end{array}$ & 29.44 \\
\hline & Intensive care & $\begin{array}{l}1 \\
1 \\
\end{array}$ & & 6,11 & 35.56 \\
\hline & $\begin{array}{l}\text { Laboratory and } \\
\text { radiology }\end{array}$ & $\begin{array}{l}5 \\
5 \\
\end{array}$ & & $\begin{array}{c}30,5 \\
6\end{array}$ & 66.11 \\
\hline & Emergency & $\begin{array}{l}2 \\
2 \\
\end{array}$ & & $\begin{array}{c}12,2 \\
2\end{array}$ & 78.33 \\
\hline & Hemodialysis & 9 & & 5,00 & 83.33 \\
\hline & Maternity & 3 & & 1,67 & 85.00 \\
\hline & Pediatrics & 8 & & 4,44 & 89.44 \\
\hline & Other & $\begin{array}{l}1 \\
9\end{array}$ & & $\begin{array}{c}10,5 \\
6\end{array}$ & 100 \\
\hline \multirow{4}{*}{$\begin{array}{l}\text { Seniority } \\
\text { in the } \\
\text { position }\end{array}$} & $1-4$ & $\begin{array}{l}7 \\
4 \\
\end{array}$ & & $\begin{array}{c}41,1 \\
1\end{array}$ & 41.11 \\
\hline & $5-9$ & $\begin{array}{l}3 \\
2 \\
\end{array}$ & & $\begin{array}{c}17,7 \\
8 \\
\end{array}$ & 58.89 \\
\hline & $10-14$ & $\begin{array}{l}1 \\
9 \\
\end{array}$ & & $\begin{array}{c}10,5 \\
6 \\
\end{array}$ & 69.44 \\
\hline & $>15$ & $\begin{array}{l}5 \\
5 \\
\end{array}$ & & $\begin{array}{c}30,5 \\
6 \\
\end{array}$ & 100 \\
\hline \multirow[t]{3}{*}{$\begin{array}{c}\text { Study } \\
\text { level }\end{array}$} & Secondary & $\begin{array}{l}2 \\
4 \\
\end{array}$ & & $\begin{array}{c}13,3 \\
3 \\
\end{array}$ & 13.33 \\
\hline & University & $\begin{array}{l}1 \\
4 \\
9 \\
\end{array}$ & & $\begin{array}{c}82,7 \\
8\end{array}$ & 96.11 \\
\hline & Other & 7 & & 3,89 & 100 \\
\hline
\end{tabular}

$* *$ ni $=$ number of staff, $\Sigma=$ sum, fi $=$ relative frequency, $\mathrm{Fi}=$ cumulative frequency

\subsubsection{Meaning given to the word "waste" by caregivers}

In $47.78 \%$ of the answers, the word «waste» was defined as dirt either a staff of $n=86,20.55 \%$ or a 
staff of $\mathrm{n}=37$ it is a residue that can no longer be used, $25.55 \%$ or a staff of $n=46$ it is an object that could be thrown away and $6.11 \%$ or a staff of $n=11$ is a useless and worthless object (Table. 2).

Table 2. Meaning of the word waste.

\begin{tabular}{|l|c|c|c|c|}
\hline & $\mathbf{N i}$ & $\Sigma$ & $\mathbf{f i}$ & $\mathbf{F i}$ \\
\hline Dirt & 86 & & 47,78 & 47,77 \\
\hline Residue & 37 & & 20,55 & 68,32 \\
\hline $\begin{array}{l}\text { Disposable } \\
\text { object }\end{array}$ & 46 & \multirow{2}{*}{180} & 25,55 & 93,87 \\
\hline $\begin{array}{l}\text { Unnecessary } \\
\text { object }\end{array}$ & 11 & & 6,11 & 100 \\
\cline { 5 - 5 } & & & & \\
\hline
\end{tabular}

\subsubsection{Knowledge of legislative and/or regulatory references}

$97.78 \%$ of participants, either a workforce $(n=176)$ did not cite any reference, legislative or regulatory in relation to the $2.22 \%$ of participants or a workforce of $(n=4)$ having cited some of the references.

\subsubsection{Knowledge of care personnel on waste separation}

$44.44 \%$ of the respondents ensure that they do not separate waste treated as household waste from other waste generated by their services. Moreover, 55.55\% say they separate them. Out of the total respondents $46.82 \%$ of them separated their waste at the source, while $53.18 \%$ said the opposite. According to the results, only $28.66 \%$ of the participants proceed with the separation of waste, while the remaining $71.34 \%$ do not respect it.

\subsubsection{Knowledge of waste collection}

In $61.67 \% \quad(n=69)$ of participants' responses, Collection is regular with a frequency of once a day. Compared to $38.33 \%$ of respondents, collection is chaotic and does not follow the normal frequency. $85.12 \% \quad(n=103)$ of health care personnel who responded to the questionnaire confirmed the existence of a person responsible for collecting hospital waste. Against $14.88 \%(n=18)$ of staff do not know. In $45 \%$ of the participants' responses, waste collection staff do not use wheeled containers for the collection of waste products services. $55 \%$ confirmed the opposite. $63.33 \%$ of responses confirm the lack of material resources (the gloves, the mask, the boots and the blouse). The waste pick-up schedules in our hospital are shown in Table 3. Indeed, $89.44 \%$ of participants confirmed that the pick-up is done in the morning and once a day, while $10.56 \%$ confirmed that pickup is done in the evening and once a day.

Table 3. Waste collection times.

\begin{tabular}{|c|c|c|c|c|}
\hline & $\mathbf{n i}$ & $\Sigma$ & $\mathbf{f i}$ & $\mathbf{F i}$ \\
\hline $\begin{array}{c}\text { Morning / 1 } \\
\text { time a day }\end{array}$ & 161 & & 89,44 & 89,44 \\
\hline $\begin{array}{c}\text { Afternoon / 1 } \\
\text { time a day }\end{array}$ & 19 & 180 & 10,56 & 100 \\
\cline { 5 - 6 }
\end{tabular}

\subsubsection{Knowledge of regulatory colour codes for waste types}

$26.11 \%(n=47)$ of participants gave the exact answer on the yellow colour code reserved for care activity waste, $59.44 \%(n=107)$ gave the exact answer on the red colour code reserved for infectious risk care activity waste and $14.44 \% \quad(n=26)$ gave the exact answer on the black colour code reserved for household waste.

\subsubsection{Staff training in solid biomedical waste management}

$12.78 \%$ or in staff $(n=23)$ of participants have already received training in hospital waste management, compared to $87.22 \%$ or $(n=157)$ have never received such training. Using this result, $76.54 \%$ of the staff at the hospital interviewed did not know how to treat their contaminated waste, compared to only $23.46 \%$ of them who did. Approximately $70 \%$ of participants confirmed the lack of a waste management plan at their health care facility.

\subsubsection{Staff awareness through hospital administration}

This graph shows that $777.78 \%(n=140)$ of the staff interviewed did not receive training in waste management, compared to only $22.22 \% \quad(n=40)$ of them who did (Figure 1).

$$
\text { Staff awareness through hospital administration }
$$

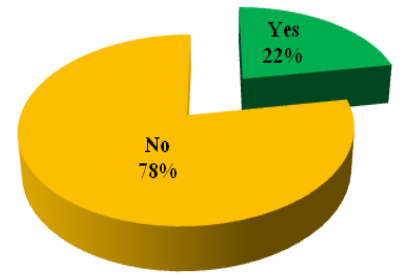

Fig. 1. Staff awareness through hospital administration.

\subsubsection{Intermediate storage and hospital facilities}

About $74.44 \%(n=134)$ of participants confirmed that there is no room for intermediate waste storage in their departments, compared to $25.56 \% \quad(n=46)$ that confirmed its existence. Only $33.13 \%$ of the workforce confirms the closing of the cover of the trash bin, $30.06 \%$ confirm the weekly washing and disinfecting the trash bins and $13.16 \%$ confirm the existence of the display for its identification. Most participants $41.77 \%(n=99)$ confirm that the most used means is manual transport, followed by a rolling machine with $29.96 \%(n=71)$, only this last is not cleaned and disinfected daily (once/week), followed by a wheelbarrow with $24.05 \%(n=57)$ and finally the other equipment represents only $4.22 \%(n=10)$. 


\subsubsection{Availability in the service of bags of different colors}

All participants $55.68 \%(n=98)$ confirmed that bags of different colors are available in their service. Only $44.32 \% \quad(n=78)$ of them believe that bags are unavailable. All participants $57.56 \% \quad(\mathrm{n}=99)$ confirmed that the quantity of bags was insufficient, while $42.44 \% \quad(n=73)$ of participants felt that the amount of bags was sufficient. $52.91 \%$ of the respondents indicated that they had a special colour coding system, and only $47.09 \%$ of them confirmed the opposite.

\subsubsection{Satisfaction of BMW management staff in the department or hospital}

$76 \%$ of staff are not satisfied with the management in their services. Only $24(n=18)$ who are satisfied with this management.

\subsection{Qualitative component}

Based on our interview with the hospital manager, we confirmed that the institution has a long-standing local policy for the management of hospital waste. This policy translates into a future vision of improving the quality and efficiency of the system put in place. Working conditions for the management of hospital waste were considered insufficient because of poor structural organization (76\%), insufficient material resources $(63.33 \%)$ and lack of procedures and protocols $(62.77 \%)$. In general, the majority did not know all the steps in the waste management process on the one hand, and on the other hand the waste management phases were insufficient due to the improper sorting of waste $(53.18 \%)$, waste collection with insufficient human resources (68.88). The pre-treatment of this waste is carried out by grinding sterilization within the hospital itself. Waste management in the hospital was satisfactory in $24 \%$. The disposal of waste outside the hospital is usually done by a provider who provides transport in an unsatisfactory manner with a frequency of one to two times a week.

\section{Discussion}

Morocco has experienced the introduction of the concept of hospital waste management and disposal with the publication of Decree No. 2-09-139 of 25 May I 1430 (21 May 2009) on the management of medical and pharmaceutical waste. This text defines different categories of medical and pharmaceutical waste and defines the methods of sorting, packaging, collection, transport and disposal of the latter. Several studies have shown that current hospital waste disposal conditions are not always satisfactory in developing countries [12, 13, 14, and 15]. Faced with this major public health problem, this study was conducted to evaluate the BMW management system at the Tangier RHC and to promote the occupational health and safety of health care personnel in the management of BMW as a result of the stated policy requirement of the institution. The absence at local level of a specific programme for the management of hospital waste is itself a major failure to ensure the proper functioning of the management system. According to the recommendations of the WHO, each care facility will have to prepare a simple waste management plan that will determine the objectives, activities, stakeholders and their responsibilities, the necessary resources, as well as the follow-up mechanisms, of supervision and control. To ensure continuity and clarity in these management practices, health care institutions must develop clear plans and policies for appropriate waste management [16]. Lack of awareness of good BMW management practice and the associated risks, insufficient human and financial resources, and inadequate disposal are the main issues related to the management of medical waste. Several series found similar results [17, 18]. More than half of the respondents reported that they had not received training on the management of BMW. Our results are comparable with those that reported that $6.25 \%$ had received training [19]. In another study [10], the majority of officers were not informed of the BMW management plan of their structure. This explains the negligence noted in the management of BMW. We make the same observation at the HASSAN II hospital in Agadir [20] and at the EL IDRISSI hospital in Kenitra [21]. El Morhit et al [22] found a low level of knowledge about DBM management among the majority of workers in four hospitals in Morocco. According to them, this explains the mismanagement of waste in four hospitals they investigated. Hence the value of integrating training and awareness into BMW management plans at institutions. Several authors found similar results [10,12, 14, and 17]. The sorting of BMW is inadequate in the majority of the hospitals surveyed and did not comply with WHO recommendations. There is lack of use of the coding system in $47.09 \%$ of hospital services. Ndiaye in Senegal [22] made the same observation. Our results are consistent with those of El Morhit [17] in Morocco, Ndiaye [12]. We observed boxes full on board with overflows. The investigating staff reported a problem with the supply of the security boxes. Azhar et al [14] found similar results in the majority of hospital departments in Dakar. Failure to fill the safety boxes is related to the lack of information and training of officers found in our study but also due to a delay in supply. Inadequate equipment and irregular staffing forces personnel to properly sort and package waste and therefore places them in situations of high risk to their health [17], and must meet quality and safety standards. The transport of BMW within the departments and to the central 
storage site is a risky step because it is carried out by manual handling or by trolley. Indeed, this transport should follow a route far from the areas frequented by patients and visitors and be carried out with the maximum safety using adjustable sanitary trolleys. This type of trolley must be easy to load, unload, clean. Our results are consistent with those reported in Rabat and Agadir [10, 17 and 18]. The waste disposal site must not be located near food warehouses or kitchens and access must be restricted to authorized personnel. It must also be easy to clean, have good lighting and ventilation and be designed so as not to allow rodents, insects and birds to enter [23]. In our study, storage sites exist in all structures, but with security noted, it is not the same in the study of Daoudi [18] conducted at the Hassan-II hospital of Agadir where there is a total absence of storage sites. Our study reveals that healthcare workers are not satisfied with waste management at the service and hospital level, according to the WHO's explanation: Customer satisfaction is one of the eight dimensions of quality. Quality is defined by AFNOR: "a quality product or service is a product whose characteristics enable it to satisfy the expressed or implied needs of consumers". The satisfaction barometer at the institutional level shows that $76 \%$ of patients and hospital users are dissatisfied with hospital hygiene and waste management. This confirms our initial problem. The satisfaction of the hospital's internal and external clients must be a lever for improvement and the institution's managers are obliged to act effectively to guarantee patients' right to health, to ensure the safety of staff and the environment and therefore to maintain the hospital's image.

\section{Conclusion}

The quality of management of solid biomedical waste in the Regional Hospital Centre (RHC) sanitary area of Tangier was unsatisfactory. The most frequently observed shortcomings were the non-existence of a management policy, the inadequate availability of material at the production sites, and the inadequate execution of the collection, transport and processing of BMW. The development and implementation of an operational plan to solve the problems identified by the various stakeholders will contribute to significantly improve the performance of BWM management at the level of the hospital studied.

\section{References}

1. M. Jean Bruno, Health Sci. Dis, 19 (April MayJune 2018)

2. L.F Diaz, S Fisher, World Health Organization. (2005)

3. P. Lakbala, M. Lakbala, Waste Manag Res, 31, 729-732 (2013)

4. D. Abiteboul, Revue francophone des laboratoires, $n^{\circ} 426$ (November 2010)
5. WHO, Memorandum Aid, 53 (2000)

6. M. Ndiaye, et al. Soc. Pathol. Exot, 105, 296-304 (2012)

7. World Health Organization (WHO). Aide mémoire $n^{\circ} 253$. Geneva, CNE. (2007)

8. National Council on the Environment CNE. 5th session. (Rabat 2007)

9. Dahir $\mathrm{n}^{\circ}$ 1-06-153 du 30 chaoual 1427 (22 novembre 2006) portant promulgation de la loi $\mathrm{n}^{\circ} 28-00$ relative à la gestion des déchets et à leur élimination. (86 Articles) -B.O. N 5480 DU 15 Kaada 1427 (7/12/2006)

10. H. Benabbess. Evaluation of the Solid Medical and Pharmaceutical Waste Management System, "Rabat Children's Hospital Case" (2014)

11. R. Mato, ME. Kaseva, Resour Conserv Recycl. 25, 271-287 (1999)

12. BS. Ndiaye. Improving biomedical waste management in a public health facility: case of the Albert Royer Children's Hospital in Dakar (2009)

13. J. Salamatou, G. Ouzounian, J. Levebre. Hospital waste. Document: Ile de France Regional Waste Observatory. 3 (1992)

14. M. azhar salim. Biomedical waste management assessment: the case of the Albert Royer Children's Hospital in Dakar. (July 2018)

15. OMS, "Recommendations for Improving Medical Waste Management", (June 2009)

16. Y. Chartier, J.mmanuel, U. Pieper, A. Prüss, P. Rushbrook, R.Stringer, et al. Second edition. Geneva: WHO (2018)

17. M. El Morhit. Evaluation of the quality of the hospital waste management system to reduce its risks on community health" case of Ibn Sina Hospital in Rabat" (December 2017)

18. M. Daoudi, Thesis. 28-9 (2008)

19. Y. Azzouzi et al. Waste management of infectious risk care activities: Sorting and conditioning, in the Gharb region of Morocco. 8, 515-528 (Sep 2014)

20. M. Ndiaye - L. El Metghari, M.M. Soumah, M.L. Sow, Senegal, Bull. Soc. Pathol. Exot, 105, 296304 (2012)

21. WHO. Preparation of National Plans for the Management of Medical Waste in Sub-Saharan Africa. In Manual for Decision Support. Secretariat of the Basel Convention, Basel Convention Series (No. 2004/4)

22. M. Ndiaye, et al. Sow. Biomedical waste management in five hospital facilities in Dakar, Senegal, Bull. Soc. Pathol. Exot. (2012)

23. OMS. Préparation des Plans Nationaux de Gestion des Déchets de soins médicaux en Afrique Subsaharienne, (2004) 